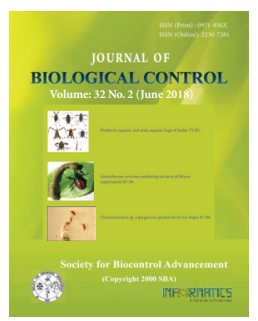

\title{
Effect of neem oil based nanoemulsion on egg parasitoid, Trichogramma chilonis (Ishii) (Hymenoptera: Trichogrammatidae)
}

\author{
S. PREETHA ${ }^{1}$, M. KANNAN ${ }^{*}$, S. LOKESH ${ }^{2}$ and V. GOWTHAM ${ }^{2}$ \\ ${ }^{1}$ Department of Nano Science and Technology, TNAU, Coimbatore - 641003, Tamil Nadu, India \\ ${ }^{2}$ Department of Agricultural Entomology, TNAU, Coimbatore - 641003, Tamil Nadu, India \\ *Corresponding author E-Mail: kanento@gmail.com
}

\begin{abstract}
Botanical biopesticides are alternative to hazardous synthetic insecticides. In the present study neem oil based nanoemulsion was synthesized using neem oil and tween 80 . The particle size was estimated as $159.2 \mathrm{~nm}$. The emulsion was characterized using particle size analyzer and TEM to confirm the formation of nano emulsion of neem oil. Trichogramma chilonis (Ishii) is an effective egg parasitoid of lepidopterous pests. It controls pests in eggs stage prior to its damaging to crops. The parasitoid is vulnerable to insecticides or oil sprays applied to the crops. The present study revealed the effects of neem nanoemulsion with $T$. chilonis under the controlled laboratory conditions. Different concentrations i.e., 50, 100, 500, 1000, 5000, $10000 \mathrm{ppm}$ were tested on T. chilonis. The biological effects viz., per cent parasitism, adult emergence were found significantly reduced and increased mortality in all the concentrations of macroemulsion of neem oil $(66.78 \pm 0.50,71.69 \pm 1.02 ; 48.45 \pm 0.35,52.26 \pm 0.60 ; 31.75 \pm 0.35,26.00 \pm 0.39$ in 10000 and 5000 ppm, respectively) as compared with nanoemulsion $(75.40 \pm 0.03,78.26 \pm 0.29 ; 52.50 \pm 0.52,57.85 \pm 0.60 ; 19.57 \pm 0.27,16.25 \pm 0.25$ in 10000 and 5000 ppm, respectively and control $(88.00 \pm 0.12 ; 82.00 \pm 1.26 ; 2.25 \pm 0.02$, respectively). These studies showed that the 10000 and 5000 ppm concentrations of nanoemulsion of neem oil were found less toxic to $T$. chilonis.
\end{abstract}

KEY WORDS: Biological effects, nanoemulsion, neem oil, Trichogramma chilonis

(Article chronicle: Received: 12-03-2018; Revised: 20-05-2018; Accepted: 14-06-2018)

\section{INTRODUCTION}

Neem, Azadirachta indica based botanical insecticides are important component of Integrated Pest Management (IPM). The main method of control has been the use of insecticides and indiscriminate application of pesticide often cuts productivity instead of improving and also causes insecticide resistance, resurgence, associated hazards to environment. Hence, there is a need for development of alternate safe technology to manage the pest problem in the future. The neem based botanical insecticides and their products are the alternatives to synthetic chemical insecticides, since botanical insecticides cause low mammalian toxicity, highly safer to beneficial, non-target organisms and environment (Miresmailli and Isman, 2014). The triterpenoid (Azadirachtin) found in seeds of the neem tree have insecticidal properties and expressed in the form of feeding and oviposition deterrence, growth inhibition, fecundity, fitness reductions (Schmutterer, 1990) and exhibits good efficacy against key insect pests in different crops. Neem products are highly photosensitivity and natural sunlight degrade the insecticidal properties; hence, neem has low residual effect under field conditions, which affects the reproducibility of the insecticide effect (Isman, 2006).
The use of nanotechnology in agriculture is getting increases in recent years. The development of controlled-release formulations of neem oil through encapsulation may improve their efficiency, since they protect the active ingredients and increasing their stability in the environment. Nanoemulsions are sub-micron oil in water emulsions with droplet diameter in nanoscale $(100-1000 \mathrm{~nm})$ and are thermodynamically stable (Solans et al., 2005).

Considering the importance of parasitoids in insect pest management, the egg parasitoids, trichogrammatids, have been reported to be efficient in regulating populations of lepidopteran pests in agricultural cropping systems (Hegazi et al., 2007). The commercial botanical neem based insecticides (azadirachtin) and their biological effects viz., level of parasitism, survival of adults or mortality, parasitoid development, adult emergence, longevity and anti-feedancy on parasitoids have to be studied in detailed. Hence, the present study is carried out to understand the biological effects of macro and nanoemulsion on the egg parasitoid, T. chilonis. 


\section{MATERIALS AND METHODS}

Neem oil was procured from Laboratory Scientific Glass Works, Coimbatore, Tamil Nadu. Tween 80 (Polysorbate 80 is a nonionic surfactant and emulsifier) was supplied by Sigma-Aldrich Limited, Bengaluru. Deionized water (ELGA DV25 Purelab option Q system from Veolia Water Technologies UK) was used for all experiments.

\section{Preparation of Neem Nanoemulsion}

The $\mathrm{O} / \mathrm{W}$ nanoemulsion was prepared using neem oil, tween 80 and water as the continuous phase. Ultrasonication of neem oil, tween 20 and water was done at $1: 3: 10$ ratios for emulsification. Ultrasonic emulsification was caused by coupling the waves of power ultrasound into a liquid system

\section{Characterization of Neem Nanoemulsion}

Horiba SZ100, particle size analyzer, Japan was used for analysis of size and size distribution of neem oil nanoemulsion. The size and distribution of the nanoemulsion was described in $\mathrm{nm}$. The surface morphology of the nanoemulsion was characterized by Transmission Electron Microscopy (TEM). A drop of nanoemulsion was placed on copper grid and allowed to dry in vacuum. The transmission electron micrographs were taken using TECNAI $120 \mathrm{Kv}$ TEM, FEI, Netherlands with a LaB6 as electron source.

\section{Effect of Neem Nanoemulsion against the Egg Parasi- toid, Trichogramma chilonis}

The effect of neem oil nanoemulsion against Trichogramma chilonis was conducted in the controlled laboratory conditions. Small glass vials were used as to conduct the experiments. Each glass vial was having an egg card of more than 1250 eggs of rice moth (Corcyra cephalonica) with four replications. Gum was spread uniformly on a piece of hard paper. The host eggs (C. cephalonica) were sprinkled on the sticky cards. These eggs cards were placed in UV radiation for 15 minutes (20 watts tube, Philips), to kill the larvae present inside the eggs. Then the egg cards were transferred to glass jars containing adults of $T$. chilonis for $1-3 \mathrm{~h}$ for parasitism. After $1-3 \mathrm{~h}$, the cards were removed and dipped in different concentrations of neem oil macro and nanoemulsion $(10000,5000,1000,500,100$ and $50 \mathrm{ppm}$, respectively), then these cards were shifted to glass vials and Data were collected on percent parasitism and adult emergence.

\section{Statistical analysis}

The data were analyzed by adopting Completely Randomized block Design (CRD) with seven treatments and three replications and the mean values of treatments were separated by Least Significant Difference (LSD) (Gomez and Gomez, 1984) using AGRES ver. (7.01), Pascal International Solutions.

\section{RESULTS AND DISCUSSIONS}

\section{Physico chemical characterization of Neem Nanoemul- sion}

The neem oil nanoemulsion showed least viscosity $(1.59 \pm 0.003$ centipoise $(\mathrm{cP}))$ compared to macroemulsion and this may be due to the increase in surfactant concentration. The nanoformualtions were found to be physically stable at room temperature and phase separation was not observed. The mean Zeta potential of nanoemulsion was $-21.42 \mathrm{mV}$ conformed that the formulation was stable. The average least droplet size of the nanoemulsion was $159.2 \mathrm{~nm}$ (Fig. 1). The results are in agreement with the findings reported by Kale and Allen (1998), They reported that addition of surfactant caused the interfacial film lead to formation of small size droplet. The result on the transmission electron microscopy assessed that the morphology of the nanoemulsion was approximately spherical in shape (Fig. 2).

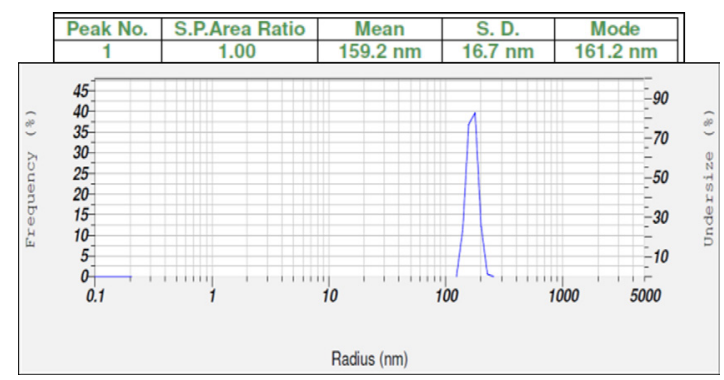

Fig. 1. Particle size analysis of neem oil nanoemulsion.

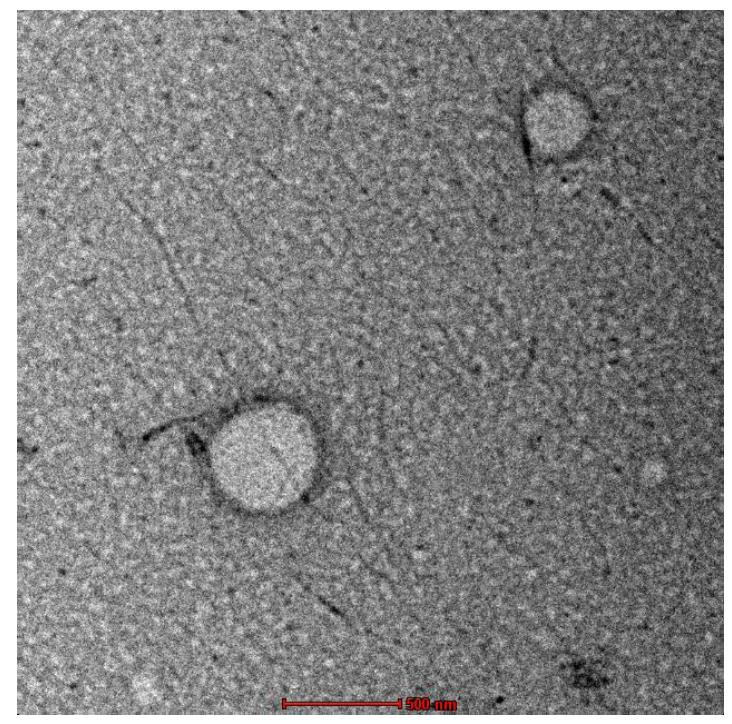

Fig. 2. Transmission electron micrograph of neem oil nanoemulsion. 


\begin{tabular}{|c|c|c|c|c|c|c|c|c|c|}
\hline 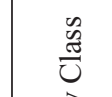 & 言㝘 & - & - & - & - & - & - & - & \\
\hline$\stackrel{0}{\cdot \vec{x}}$ & 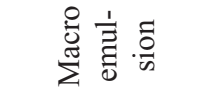 & - & - & - & - & - & $N$ & - & \\
\hline \multirow{2}{*}{ 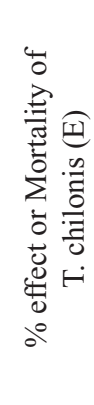 } & 离 & $\begin{array}{l}0 \\
0 \\
0 \\
+1 \\
0 \\
0 \\
n \\
n \\
m\end{array}$ & $\begin{array}{l}0 \\
0 \\
+ \\
+1 \\
0 \\
\infty \\
\dot{0} \\
\dot{1}\end{array}$ & $\begin{array}{l}m \\
0 \\
0 \\
+1 \\
0 \\
0 \\
0 \\
0\end{array}$ & \begin{tabular}{l}
$n$ \\
0 \\
0 \\
+1 \\
0 \\
\multirow{2}{0}{} \\
0 \\
0
\end{tabular} & 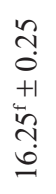 & 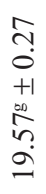 & \multirow{2}{*}{ 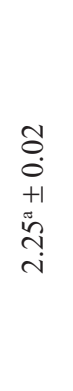 } & $\begin{array}{l}\stackrel{\infty}{1} \\
\stackrel{0}{0}\end{array}$ \\
\hline & 这 & $\begin{array}{l}0 \\
0 \\
0 \\
+1 \\
0 \\
\infty \\
0 \\
r\end{array}$ & 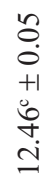 & 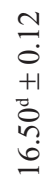 & $\begin{array}{l}\text { ते } \\
0 \\
+1 \\
0 \\
0 \\
0 \\
\dot{\lambda}\end{array}$ & 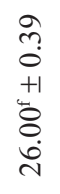 & $\begin{array}{l}m \\
m \\
o \\
+1 \\
\text { son } \\
\stackrel{n}{n} \\
\dot{m}\end{array}$ & & $\begin{array}{l}\stackrel{J}{ \pm} \\
\stackrel{0}{0}\end{array}$ \\
\hline \multirow{2}{*}{ 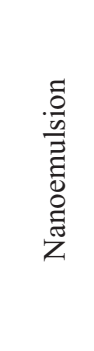 } & 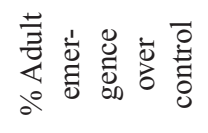 & $\stackrel{n}{o}$ & $\begin{array}{l}\overrightarrow{0} \\
\stackrel{0}{0}\end{array}$ & $\underset{8}{8}$ & $\stackrel{\sim}{\stackrel{\sim}{d}}$ & $\begin{array}{l}\infty \\
\infty \\
\stackrel{i}{i}\end{array}$ & 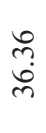 & ' & ' \\
\hline & 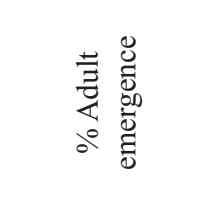 & $\begin{array}{l}m \\
m \\
0 \\
+1 \\
\infty \\
\infty \\
2 \\
2\end{array}$ & 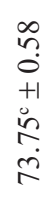 & $\begin{array}{l}\vec{\sim} \\
0 \\
+1 \\
\overrightarrow{0} \\
\dot{+} \\
0 \\
0\end{array}$ & $\begin{array}{l}\vec{n} \\
0 \\
+1 \\
0 \\
0 \\
0 \\
0\end{array}$ & $\begin{array}{l}n \\
n \\
0 \\
+1 \\
i n \\
\infty \\
i n \\
i n\end{array}$ & $\begin{array}{l}n \\
n \\
0 \\
+1 \\
\text { on } \\
\text { ñ } \\
i n \\
n\end{array}$ & 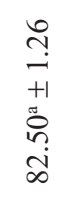 & $\stackrel{ }{\text { ㄱ. }}$ \\
\hline \multirow{2}{*}{ 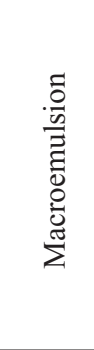 } & 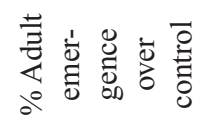 & ర్ర్ర & $\stackrel{1}{0}$ & $\stackrel{?}{\stackrel{2}{I}}$ & $\begin{array}{l}\stackrel{8}{+} \\
\stackrel{+}{+}\end{array}$ & $\stackrel{\stackrel{n}{+}}{i}$ & $\stackrel{\infty}{m}$ & ' & ' \\
\hline & 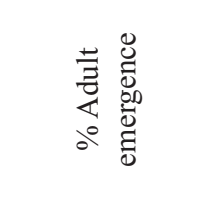 & 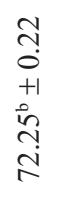 & $\begin{array}{l}\vec{\jmath} \\
0 \\
+1 \\
0 \\
0 \\
0 \\
0\end{array}$ & $\begin{array}{l}\hat{n} \\
0 \\
+1 \\
0 \\
0 \\
0 \\
0 \\
0\end{array}$ & $\begin{array}{l}0 \\
0 \\
0 \\
+1 \\
0 \\
0 \\
\infty \\
\infty \\
i n\end{array}$ & $\begin{array}{l}8 \\
0 \\
0 \\
+1 \\
\stackrel{0}{0} \\
\text { in } \\
\text { ñ }\end{array}$ & 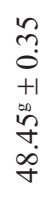 & 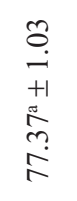 & $\begin{array}{l}\stackrel{n}{\sigma} \\
\stackrel{0}{0}\end{array}$ \\
\hline \multirow{2}{*}{ 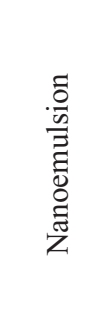 } & 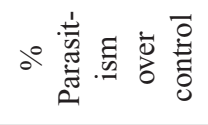 & $\stackrel{8}{0}$ & 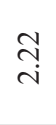 & $\begin{array}{l}\text { ñ } \\
i n\end{array}$ & $\underset{\infty}{\infty}$ & 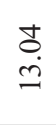 & ָู & ' & ' \\
\hline & 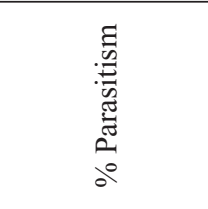 & $\begin{array}{l}\text { I } \\
3 \\
+1 \\
+1 \\
8 \\
8 \\
8\end{array}$ & 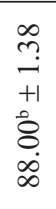 & $\begin{array}{l}8 \\
0 \\
0 \\
+1 \\
0 \\
8 \\
0 \\
\infty\end{array}$ & $\begin{array}{l}0 \\
0 \\
0 \\
+1 \\
+ \\
0 \\
0 \\
i \\
\infty \\
\infty\end{array}$ & 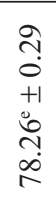 & $\begin{array}{l}\tilde{0} \\
\dot{0} \\
+1 \\
+1 \\
\dot{q} \\
\dot{q}\end{array}$ & $\begin{array}{l}1 \\
0 \\
0 \\
+1 \\
8 \\
8 \\
8 \\
8\end{array}$ & $\begin{array}{l}\hat{\infty} \\
0 \\
0\end{array}$ \\
\hline \multirow{2}{*}{ 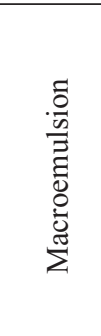 } & 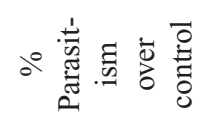 & $\widehat{\widehat{N}}$ & $\widehat{ָ}$ & $\vec{m}$ & $\begin{array}{l}\dot{\sigma} \\
\dot{-}\end{array}$ & $\begin{array}{l}n \\
n \\
\infty\end{array}$ & $\underset{J}{\stackrel{ \pm}{ \pm}}$ & ' & ' \\
\hline & 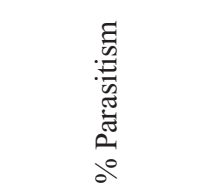 & $\begin{array}{l}\tilde{N} \\
0 \\
+1 \\
+1 \\
0 \\
0 \\
0 \\
\infty\end{array}$ & $\begin{array}{l}\tilde{a} \\
\stackrel{1}{+} \\
+1 \\
\dot{8} \\
\dot{0}\end{array}$ & $\begin{array}{l}n \\
0 \\
+1 \\
+1 \\
\vdots \\
0 \\
\dot{\infty}\end{array}$ & 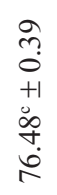 & 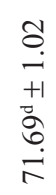 & $\begin{array}{l}0 \\
0 \\
0 \\
+1 \\
0 \\
0 \\
0 \\
0 \\
0\end{array}$ & \begin{tabular}{l}
\multirow{1}{*}{} \\
0 \\
+1 \\
+1 \\
0 \\
0 \\
$\infty$ \\
$\infty$
\end{tabular} & $\begin{array}{l}\vec{\Xi} \\
\stackrel{0}{0}\end{array}$ \\
\hline & 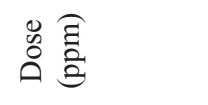 & in & 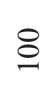 & \& & $\stackrel{\Xi}{~}$ & \&ి & ఏ & 它 & $\stackrel{8}{\circ}$ \\
\hline & 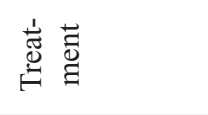 & $F$ & $\stackrel{\sim}{F}$ & $\hat{\ominus}$ & $\stackrel{\rightleftarrows}{\oplus}$ & 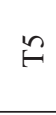 & $\stackrel{\bullet}{\bullet}$ & $\hat{F}$ & ปั้ \\
\hline
\end{tabular}




\section{Effect of Neem Nanoemulsion against the Egg Parasi- toid, Trichogramma chilonis}

Results presented in Table 1 showed the effect of different concentrations of nanoemulsion in comparison with macroemulsion of neem oil on the percent parasitism, adult emergence and mortality of $T$. chilonis. All these treatments were significantly different from one another. Highest percent parasitism was observed in control $(90.00 \%)$. The data showed that parasitism was significantly decreased by increasing the neem oil macroemulsion concentrations (T1T5). On the contrary, the parasitism was significantly higher in neem oil nanoemulsion $(86.00,86.00,80.69,76.48$, 71.69 and 66.78 in 50, 100, 500, 1000, 50000, $10000 \mathrm{ppm}$, respectively) than neem oil macroemulsion. The lowest percent adult emergence (48.45\%) was recorded in the highest concentration (T6) of neem oil macro emulsion followed by $52.26,58.80,63.63,69.50$ and $72.25 \%$ in T5, T4, T3 T2 and $\mathrm{T} 1$, respectively. Highest adult emergence (82.50 and $77.37 \%$ in neem nano and macroemulsion) was recorded in check (T6). The adult emergence was found on increasing rate by decreasing the concentrations of neem nano and macroemulsions.

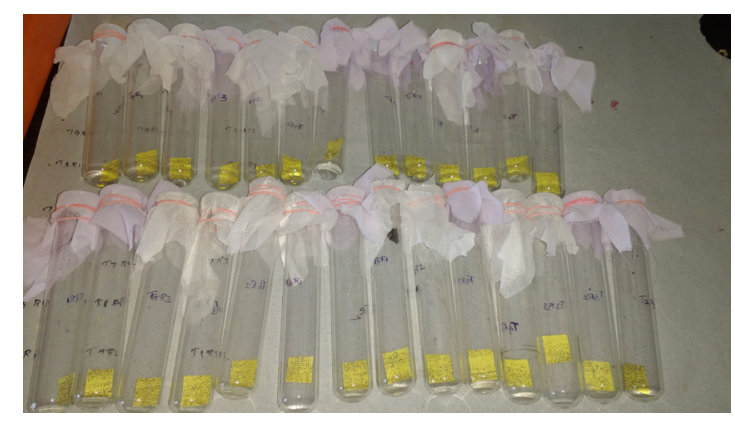

Fig. 3. Effects of neem oil nanoemulsion on the egg parasitoid, Trichogramma chilonis.

The results also revealed that significantly higher number of black eggs was observed in control and neem oil nanoemulsion. The different concentrations of macroemulsion were proved to be toxic when they used in higher concentrations. The same trend was also observed in percent parasitism, adult emergence and mortality. The results are in agreement with earlier reports of Lakshmi et al., 2004 and Lyons et al., 2003. They reported that, Azatin Ec and Neem Ec significantly affect the parasitism of $T$. chilonis after $24 \mathrm{~h}$ at higher concentrations as compared with the lowest ones. Rao et al. (2002), Jalali. and Singh (2003) reported that neem formulations, while Lannacone and Lamas (2003) reported that rotenone as well as neem both at highest doses significantly affected longevity of $T$. chilonis.

\section{ACKNOWLEDGEMENTS}

The authors express sincere thanks to The Professor and Head, Department of Nano Science and Technology and The Professor and Head, Department of Agricultural Entomology, Tamil Nadu Agricultural University, Coimbatore for providing the facilities to carry out the studies.

\section{REFERENCES}

Gomez KA, Gomez AA. 1984. Statistical Procedure for Agricultural Research. $2^{\text {nd }}$ ed. John Willey and Sons.

Hegazi E, Herz A, Hassan SA, Ekhafagi W, Agamy E, Zaitun A, Gehan AE, Showeil S, ElSaid S, Khamis N. 2007. Field efficiency of indigenous egg parasitoids hymenoptera, Trichogrammatidae) to control the olive moth Prays oleae (Lepidoptera, Yponomeutidae) and the jasmine moth Palpita unionalis (Lepidoptera, Pyralidae) in an olive plantation in Egypt. Biol Control 43: 171187. https://doi.org/10.1016/j.biocontrol.2007.07.009.

Isman MB. 2006. Botanical insecticides, deterrents, and repellents in modern agriculture and an increasingly regulated world. Annu Rev Entomol. 51: 45-66. https:// doi.org/10.1146/annurev.ento.51.110104.151146 PMid:16332203.

Jalali, S. K. and Singh, S. P. 2003. Effect of neem product and bio-pesticides on egg parasitoid Trichogramma chilonis Ishii. J Appl Zool Res. 14: 125-128.

Kale NJ, Allen AV. 1998. Studies on microemulsions using Brij-96 as surfactant and glycerin, ethylene glycol and propylene glycol as cosurfactants. Int J Pharm. 57: 87-93. https://doi.org/10.1016/0378-5173(89)90296-2.

Lannacone OJ, Lamas MG. 2003. Toxicological effects of extracts of Peruvian pepper tree (Schimes molle) and lantana on Chrysoperla externa, Trichogramma pintoi and Copidonoma koenleri in Peru. Agric Tecnica 163: 347-360.

Lakshmi VJ, Katti G, Krishnaiah NV, Lingaiah T. 2004. Laboratory evaluation of commercial neem formulations vis-a-vis insecticides against egg parasitoid, Trichogramma japonicum Ashmead (Hymenoptera: Trichogrammatidae). J Biol Control 11: 1-2.

Lyons DB, Helson BV, Bourchier RS, Jones GC, Mcfarlane JW. 2003. Effects of azadirachtin-based insecticides on the egg parasitoid Trichogramma minutum (Hymenoptera: Trichogrammatidae). Can Entomol. 135: 685-695. https://doi.org/10.4039/n02-113. 
Miresmailli S, Isman MB. 2014. Botanical insecticides inspired by plant-herbivore chemical interactions. Trends Plant Sci. 19: 29-35. https://doi.org/10.1016/j. tplants.2013.10.002 PMid:24216132.

Rao NBVC, Goud TR, Gour TB. 2002.Toxicity of newer insecticides to egg parasitoid, Trichogramma chilonis ISHH. J Res Angrau, 30(2): 124-126.
Schmutterer H. 1990. Properties and potential of natural pesticides from the neem tree, Azadirachta indica. Ann Rev Ent. 35: 271-297. https://doi.org/10.1146/ annurev.en.35.010190.001415 PMid:2405771.

Solans C, Izquierdo P, Nolla J, Azemar N, Garcia-Celma MJ. 2005. Nano-emulsions. Curr Opin Colloid Interface Sci. 10: 102-110. https://doi.org/10.1016/j. cocis.2005.06.004. 